\title{
Preparation, Characterization and Evaluation of Docetaxel-loaded, Folate-conjugated PEG-liposomes
}

\author{
Zhengui YuAn, ${ }^{a}$ Dawei CHen, ${ }^{*},{ }^{a}$ Shoutang ZHANG, ${ }^{b}$ and Zhendong ZHENG ${ }^{c}$ \\ ${ }^{a}$ School of Pharmacy, Shenyang Pharmaceutical University, Shenyang, 110016 P. R. China, \\ ${ }^{b}$ Department of Pharmacy, People's Armed Police Corps Hospital of Heilong Jiang \\ Province, Harbin, 150076 P. R. China, and 'Department of Oncology, General \\ Hospital of Shenyang Military Region, Shenyang, 110840 P. R. China
}

(Received March 5, 2010; Accepted May 17, 2010)

For the purpose of enhancing the anticancer potency of docetaxel, a novel excipient, cholesterol-PEG-folate $(\alpha-$ (3.beta) cholest-5-en-3- $\omega$-folic acid-poly (oxy-1, 2-ethanediyl)), was synthesized and used for the preparation of liposomes (folate-conjugated PEG-liposomes). The in vitro release properties, in vitro cytotoxicity, in vivo pharmacokinetics and distribution, as well as in vivo potency of the liposomes were evaluated. These liposomes were able to control the release of the loaded drug. Docetaxel-loaded, folate-conjugated PEG-liposomes were more cytotoxic to MCF-7cells than ordinary PEG-liposomes. The pharmacokinetic parameters of folate-conjugated PEG-liposomes were studied in rats. Compared to docetaxel solution, the folate-conjugated PEG-liposomes enhanced the $t_{1 / 2}$ of docetaxel by 6.74 -fold. The biodistributions of docetaxel in the heart, brain and kidneys decreased when delivered in liposomes. The folate-conjugated PEG-liposomes could significantly enhance tumor accumulation of docetaxel and antitumor activity in tumorbearing mice $(p<0.05)$. The precent results indicate that these folate-conjugated PEG-liposomes might enhance the potency while preventing the side effects of docetaxel.

Key words—_ docetaxel; folate-conjugated; PEG-liposome; preparation; evaluation; anticancer

\section{INTRODUCTION}

Over the past few decades, increasing attention has been given to drug targeting in order to reduce sideeffects and improve therapeutic efficacy by preventing undesired drug localization in healthy tissue sites and decreasing the rapid degradation or elimination of drugs.

Docetaxel (N-debenzoyl-N-tert-butoxycarbonyl10-deacetyl paclitaxel) is a semi-synthetic derivative of the taxoid family of antineoplastic agents. It is an analog of paclitaxel which is extracted from the needles of the European yew tree (Taxus baccata L.).1) Docetaxel has been effective against breast, ovarian, lung, and head and neck cancers. Being a microtubule stabilizing agent, it inhibits microtubule disassembly and consequently inhibits cell proliferation. ${ }^{2)}$ To overcome the poor solubility of docetaxel and to improve its efficacy, novel formulations have been introduced. Docetaxel-loaded liposomes were prepared and achieved a better antitumor activity and a longer circulation time in the body. ${ }^{3)}$ Docetaxel-encapsulating nanoparticles formulated with poly ( $\mathrm{D}, \mathrm{L}$-lactic-

*e-mail: chendawei @ syphu.edu.cn co-glycolic acid) -block-poly (ethylene glycol) (PLGAb-PEG) copolymer, and surface functionalized with the A 10 2'-fluoropyrimidine RNA aptamers, were found to exhibit remarkable efficacy and reduced toxicity. ${ }^{4)}$ A pegylated liposomal formulation of docetaxel was also developed with the purpose of improving docetaxel solubility without any need to use Tween 80 and of enhancing stability in the blood circulation. ${ }^{5}$

Although these formulations have some advantages, there are still some problems that need to be solved for them to meet the requirements for clinical use and industrial production. Targeting the folate receptor has shown considerable promise in mediating the uptake of a variety of drugs when folic acid is conjugated to the drug or delivery vehicle. ${ }^{6-10)}$ Differential expression of the folate receptor has been exploited to target liposomes to tumors. Tumor cells that vastly over-express the folate receptor showed significant uptake of folate targeted anti-cancer drug, while normal cells that do not express the folate receptor took up minimal amounts of the drug. ${ }^{6}$ Cholesterol is frequently included in liposomes to control the release of the entrapped drugs ${ }^{11}$ or to enhance the stability of the formulations. ${ }^{12-14)}$ In this 
study, a folate-conjugated and pegylated cholesterol, cholesterol-PEG-folate ( $\alpha$ - (3.beta) cholest-5-en-3- $\omega$ folic acid-poly (oxy-1, 2-ethanediyl)), was synthesized, and liposomes containing this reagent were evaluated.

\section{MATERIALS AND METHODS}

Materials Docetaxel (purity $>99.5 \%$ ) was obtained from Jiangsu Hengrui Medicine Co., Ltd. (Lianyungang, China). Cholesterol- $N$ - [methoxy poly (ethylene glycol)-2000] (PEG-Cholesterol) was purchased from Nippon Oil and Fats Corporation (Tokyo, Japan). Soya phosphatidylcholine (PC, 95\% purity) was purchased from Shanghai Taiwei Pharmaceutical Industry Co., Ltd. (Shanghai, China), and cholesterol was from Sigma-Aldrich Co. (St. Louis, MO, USA). All other reagents were of analytical grade.

Synthesis of Cholesterol-PEG-Folate ( $\alpha$-(3.beta) cholest-5-en-3- $\omega$-Folic acid-Poly (oxy-1, 2-ethanediyl))

To a mixture of PEG-cholesterol $(240 \mathrm{mg})$ and folic acid $(59 \mathrm{mg})$ in $5 \mathrm{ml}$ dimethylformamide, $\mathrm{N}, \mathrm{N}^{\prime}$ dicyclohexyl carbodiimide $(105 \mathrm{mg})$ was added, and the mixture was stirred for $48 \mathrm{~h}$ at room temperature under nitrogen gas. After the reaction, the mixture was filtered and the filtrate was evaporated to about 2 $\mathrm{ml}$ under reduced pressure. Ether $(20 \mathrm{ml})$ was added to precipitate the product. After filtration, the residue was dissolved in $10 \mathrm{ml}$ acetone, re-crystallized and dried to obtain the final product.

Animals Male Sprague-Dawley rats (240-260 g) and mice (18-22 g) were provided by the Experimental Animal Center of Shenyang Pharmaceutical University (Shenyang, China). BALB/c nude mice were purchased from Shanghai Institute of Biochemistry and Cell Biology (Shanghai, China). The animal experimentation was approved by the Animal Ethics Committee of Shenyang Pharmaceutical University and was performed in accordance with the Guidelines for Animal Experimentation of the university. Animals were maintained under standard laboratory conditions on a $12 \mathrm{~h} / 12 \mathrm{~h}$ light/dark cycle and were fed standard rat chow and water ad libitum. Animals were fasted overnight before the experiment.

\section{Preparation of Folate-conjugated PEG-liposomes}

The liposomes were prepared by the hydration of a dried, thin layer of lipid,15) obtaining multilamellar vesicles $(\mathrm{MLV})$. In brief, the lipid phase (consisting of a mixture of $300 \mathrm{mg}$ PC, $100 \mathrm{mg}$ cholesterol,
Cholesterol-PEG-Folate and Cholesterol-PEG (PC: Cholesterol-PEG-Folate: Cholesterol-PEG = 100:1:5 molar ratio) and docetaxel $(15 \mathrm{mg})$ were dissolved in $10 \mathrm{ml}$ of chloroform in a clean $100 \mathrm{ml}$ round bottom flask. The solvent was then removed under reduced pressure using a rotary evaporator at $40^{\circ} \mathrm{C}$, thus obtaining a thin film of dry lipid on the wall of the flask. Evaporation was continued for $2 \mathrm{~h}$ to remove the traces of organic solvent after the dry residue appeared. Finally, the film was hydrated by adding 10 $\mathrm{ml}$ of phosphate buffered saline at $50^{\circ} \mathrm{C}$, under vigorous stirring in order to facilitate the formation of vesicles. Small unilamellar vesicles were prepared from the MLV suspensions by ultrasonication (400 w, 5 min) using a Scientz-IID ultrasonic homogenizer (Ningbo Scientz Biotechnology Co., Ltd, Ningbo, China). the liposomes were then filtered through a $0.22 \mu \mathrm{m}$ filter (Millipore Corp., Bedford, Mass.) and stored at $4^{\circ} \mathrm{C}$.

As a control, "ordinary liposomes" and "PEG liposomes" were also prepared by the same procedure.

Measurement of Encapsulation Efficiency The content of docetaxel in the liposomes was quantified by the HPLC method described below and served as $100 \%$ for determination of the encapsulation efficiency. Four hundred microliters of liposomes were centrifuged in an Eppendorf centrifuge $(11,000 \times \mathrm{g}, 20$ min) through a Microcon YM-10 Centrifugal Filter Device (Millipore) with a cut-off value of $10 \mathrm{kDa}$. The concentration of docetaxel in the filtrate, representing the amount of free drug, was also determined by the HPLC method. A Hypersil ODS C18 column $(4.6 \times 150 \mathrm{~mm}, 5 \mu \mathrm{m}$, Dalian Elite Analytical Instruments Co., Ltd.) was used. The mobile phase consisted of a mixture of acetonitrile and water $(55: 45, \mathrm{v} / \mathrm{v})$ delivered at a flow rate of $1.0 \mathrm{ml} / \mathrm{min}$. The injection volume was $20 \mu \mathrm{l}$ and the wavelength was set at $230 \mathrm{~nm}$. The column temperature was $25^{\circ} \mathrm{C}$.

Size and Size Distribution The particle size and the size distribution of liposomes were determined by an LS 230 laser diffraction particle size analyser (Beckman Coulter, CA, USA). The liposomes were dispersed in distilled water and the size was measured. The analysis was performed three times and the average values were taken.

In Vitro Release Folate-conjugated PEG Liposomes In vitro release studies were performed using an Intellectual Diffusion Meter. Dialysis bags with 
a molecular weight cut-off value of $\sim 10,000$ were used. The membrane was soaked in double-distilled water for $12 \mathrm{~h}$ before use. Liposomes $(2 \mathrm{ml}$ ) were placed in the dialysis bag and were tied onto the paddles of the diffusion meter. The paddles and dialysis bags were immerged into $50 \mathrm{ml}$ of dialysis medium $(0.5 \%$ Tween 80 solution) and the paddles were stirred at a rate of $50 \mathrm{rpm}$ at $37^{\circ} \mathrm{C}$. The dialysis medium was withdrawn in $1 \mathrm{ml}$ aliquots at $0.5,1,2,3,4,6$, 8,12 and $24 \mathrm{~h}$ and replaced with fresh dialysis medium of the same temperature was placed to maintain a constant volume. Samples were analyzed by the HPLC method described above.

In Vitro Cytotoxicity of Folate-conjugated PEG Liposomes MCF-7 and HeLa cells were obtained from the American Type Culture Collection (Rockville, MD, USA $)$. The cells $\left(1 \times 10^{4}\right.$ cells/well $)$ were seeded into 96-well microplates and cultured for $24 \mathrm{~h}$ in RPMI 1640 medium with $10 \%$ fetal bovine serum (FBS) at $37^{\circ} \mathrm{C}$. The seeding medium was then removed and replaced by experimental medium. Cells were maintained for $24 \mathrm{~h}$ in medium supplemented with docetaxel-loaded, folate-conjugated PEG liposomes or PEG liposomes, drug-free, folate-conjugated PEG liposomes or free docetaxel. After incubation, plates containing cells were washed with fresh medium to remove unbound liposomes and cellular debris. Cell viability was assessed by MTT [3- (4,5-sdimethylthiazol-2-yl) -2,5-diphenyl tetrazolium bromide] assay. Each condition was performed in sextuplicate. Cytotoxicity was expressed as a percentage of control. The $50 \%$ inhibitory concentration $\left(\mathrm{IC}_{50}\right)$, defined as the dose of compound that inhibited 50\% of cell growth, was interpolated from the growth curves thus obtained.

Pharmacokinetic Studies Fifteen rats were divided into three groups of 5 animals each. The rats in each group were administered docetaxel solution, folate-conjugated PEG-liposomes or PEG-liposomes i.v. at a dose of $15 \mathrm{mg} / \mathrm{kg}$. Blood samples $(\sim 500 \mu \mathrm{l})$ were collected at $0.083,0.25,0.5,1,2,4,8,12$ and 24 $\mathrm{h}$ after administration. Blood samples were placed in heparinized tubes, immediately centrifuged, and stored at $-20^{\circ} \mathrm{C}$ until analysis.

The plasma concentration of docetaxel was assayed by an LC-UV method after the samples were pretreated by a liquid-liquid extraction method. Briefly, to $200 \mu \mathrm{l}$ aliquot of plasma sample, $10 \mu \mathrm{l}$ of methanol (containing diazepam as internal standard, $25 \mu \mathrm{g}$ / ml) was added. Samples were then vortex-mixed for 3 min and extracted with $2.0 \mathrm{ml}$ ether by vortex-mixing for $5 \mathrm{~min}$. After centrifugation at $4500 \times \mathrm{g}$ for $5 \mathrm{~min}$, the upper organic layer was transferred to another tube and evaporated to dryness at $45^{\circ} \mathrm{C}$ under a gentle stream of nitrogen. The residue was reconstituted in $100 \mu \mathrm{l}$ methanol followed by vortex-mixing for 3.0 min and centrifugation at $4500 \times g$ for $5 \mathrm{~min}$. A $20 \mu \mathrm{l}$ aliquot of the supernatant was then injected onto the LC-UV system. The separation was performed by a Hypersil C18 column $(4.6 \times 150 \mathrm{~mm}, 5.0 \mu \mathrm{m}$, Dalian Elite Analytical Instruments Co., Ltd). The mobile phase consisted of a mixture of acetonitrile and water $(48: 52, \mathrm{v} / \mathrm{v})$ delivered at a flow rate of $1.0 \mathrm{ml} / \mathrm{min}$. The injection volume was $20 \mu \mathrm{l}$ and the wavelength was set at $230 \mathrm{~nm}$. The column temperature was $25^{\circ} \mathrm{C}$.

All pharmacokinetic parameters were determined by non-compartmental analysis. The elimination rate-constant $\left(K_{\mathrm{e}}\right)$ was calculated from the slope of the logarithm of the plasma concentration versus time using the final four points. The apparent elimination half-life $\left(t_{1 / 2}\right)$ was calculated as $0.693 / K_{\mathrm{e}}$. The area under the plasma concentration-time curve ( $A U C$, area under the curve) and the area under the first moment curve $(A U M C)$ were calculated by the trapezoidal rule. Total body clearance $(C L)$ was calculated as Dose/AUC. The mean residence times (MRT) were calculated by dividing $A U M C$ by $A U C$. Each value is expressed as the mean \pm S.D.

Biodistribution Studies Thirty-six mice were randomly divided into 3 groups of 12 mice. The mice were administered free docetaxel, folate-conjugated PEG-liposomes or PEG-liposomes i.v. at a dose of 15 $\mathrm{mg} / \mathrm{kg}$. The animals were sacrificed, and selected tissues, including plasma, brain, heart, liver, spleen, lung and kidney were collected at 0.5, 2, 6 and $12 \mathrm{~h}$ after drug administration. The tissues were excised, and rinsed with ice-cold physiological saline. Then the tissues were weighed accurately, cut into slices and homogenized in a ground glass tissue grinder after adding the appropriate amount of methanol $(3 \mathrm{ml} / \mathrm{g}$ tissue). The uniform homogenates were immediately stored at $-20^{\circ} \mathrm{C}$ until analysis. Tissue homogenates were pretreated and assayed according to the same procedure as those of plasma samples.

Thirty-six nude Balb/c mice were raised in the SPF laboratory (class II), and used when they were 6 weeks old. MCF-7 cells $\left(200 \mu \mathrm{l}, 5 \times 10^{6}\right)$ in log phase growth were implanted into their axillary fossas. 
When the tumor diameters had reached $1.0 \mathrm{~cm}$, the mice were used for further studies. Thirty-six tumorbearing mice were randomly divided into 3 groups of 12 mice each. The mice were administered free docetaxel, folate-conjugated PEG-liposomes or PEG-liposomes i.v. at a dose of $15 \mathrm{mg} / \mathrm{kg}$. The animals were sacrificed, and tumor tissues were collected at $0.5,2,6$ and $12 \mathrm{~h}$ after drug administration. The docetaxel concentrations in the tumors were determined using the same method as that for tissue samples.

Evaluation of in Vivo Anti-tumor Activity Tumorbearing mice were prepared by inoculating a suspension of MCF-7 cells $\left(2 \times 10^{6}\right.$ cells per mouse) s.c. into each axillary fossa of nude BALB/c mice. After 5 days, a palpable tumor was observed and the mice were used for further studies. Twenty mice were divided into 4 groups. Blank PBS, docetaxel solution, folate-conjugated PEG-liposomes or PEG-liposomes were injected twice into the tumor-bearing mice via the tail vein at a dose of $10 \mathrm{mg} / \mathrm{kg}$ every other day for 5 days. On day 16 after tumor cell inoculation, the mice were sacrificed, and the tumor volumes were calculated using the formula $0.5 \times\left(A \times B^{2}\right)$, where $A$ and $B$ are the longest and shortest dimensions (mm) of the tumor, respectively.

Statistical Analysis Differences between folateconjugated PEG-liposomes and docetaxel solution or PEG-liposomes were compared with Student's unpaired $t$-test. A $p$ value $<0.05$ was considered statistically significant.

\section{RESULTS AND DISCUSSION}

\section{Characterization of Folate-conjugated PEG-lipo-} somes The particle size distribution of the folateconjugated PEG-liposomes prepared in this study showed a unimodal distribution and the average diameter was $117 \mathrm{~nm}$. The entrapment efficiency of the liposomes was $72.51 \pm 1.34 \%$.

\section{In Vitro Release of Folate-conjugated PEG-lipo-} somes The release profiles of docetaxel from solution, folate-conjugated PEG-liposomes and PEGliposomes are shown in Fig. 1. As expected, a burst of release of drugs from both liposomes at $37^{\circ} \mathrm{C}$ was observed. Then, the entrapped drug was released slowly from both types of liposomes and about $30 \%$ of the drug still remained in the folate-conjugated PEGliposomes after $24 \mathrm{~h}$.

In Vitro Cytotoxicity of Folate-conjugated PEG

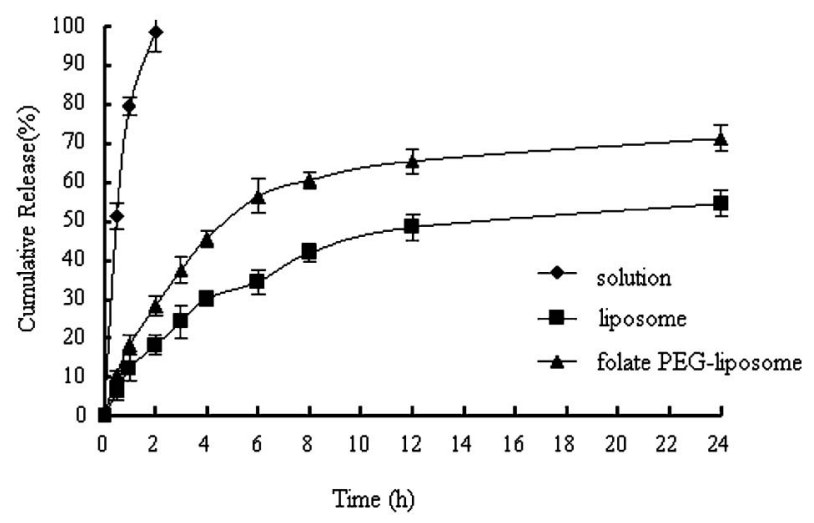

Fig. 1. Cummulative Release of Docetaxel from Drug Solution and Two Drug Loaded Liposome Formulations

Table 1. Cytotoxicity Effect of Various Formulations of Docetaxel on MCF-7 Cells and Hela Cells

\begin{tabular}{lcc}
\hline \hline \multirow{2}{*}{ Formulation } & \multicolumn{2}{c}{$\mathrm{IC}_{50}(\mu \mathrm{mol} / \mathrm{ml})$} \\
\cline { 2 - 3 } & SMMC-7721 cells & HeLa cells \\
\hline DTX & $1.15 \pm 0.42$ & $2.44 \pm 0.51$ \\
Fol-PEG-DTXL & $18.75 \pm 2.47$ & $63.14 \pm 5.41$ \\
PEG-DTXL & $56.47 \pm 3.31$ & $66.23 \pm 6.72$ \\
DTXL & $42.17 \pm 4.75$ & $50.63 \pm 5.16$ \\
Folic acid & $\mathrm{NE}$ & $\mathrm{NE}$ \\
Empty Liposomes & $\mathrm{NE}$ & $\mathrm{NE}$ \\
\hline
\end{tabular}

DTX, docetaxel solution; Fol-PEG-DTXL, docetaxel-loaded, folateconjugated PEG-liposomes; PEG-DTXL, docetaxel loaded PEG-liposomes; DTXL, docetaxel loaded liposome.

Liposomes Table 1 shows the concentrations of docetaxel either in solution, or in various liposomes that caused 50\% inhibition of cell growth after a $24 \mathrm{~h}$ exposure.

No cytotoxicity of the unloaded liposome or a folic acid solution was observed in either cell-line studied. The MCF-7 cells were more sensitive than the HeLa cells to docetaxel either in solution or in liposomes. The concentrations of docetaxel required to achieve $50 \%$ growth inhibition in both cell lines were much lower in solution than in the liposomes. The lower $\mathrm{IC}_{50}$ values of the free drug in the two cell lines might be caused by the short incubation time of the experiment. A lower $\mathrm{IC}_{50}$ was reported for free docetaxel than for ordinary liposomes and PEGylated liposomes after a $2 \mathrm{~h}$ incubation, while the liposome formulations were almost equipotent with free docetaxel in the two cell lines after a $48 \mathrm{~h}$ incubation. ${ }^{3)}$

The docetaxel-loaded, folate-conjugated PEG liposomes were more cytotoxic than the other docetaxel- 
loaded liposomes against MCF-7 cells, while all three docetaxel-loaded liposomes showed similar cytotoxicity against HeLa cells.

Pharmacokinetic Studies The plasma concentration vs time of docetaxel obtained after the injection of the three formulations is shown in Fig. 2. After injection of folate-conjugated PEG-liposomes, the docetaxel concentration was still measurable after $36 \mathrm{~h}$, while the drug injected free in solution was not detectable even after $12 \mathrm{~h}$. A difference in the docetaxel concentration between the two kinds of liposomes was observed; the folate-conjugated PEGliposomes were generally present in blood at higher concentrations than the non-stealth liposomes.

The comparative pharmacokinetic parameters after i.v. administration of the docetaxel formulations are shown in Table 2. The folate-conjugated PEG-liposomes significantly enhanced the half-life of docetaxel.

Biodistribution Studies Tissue distributions af-

(A)

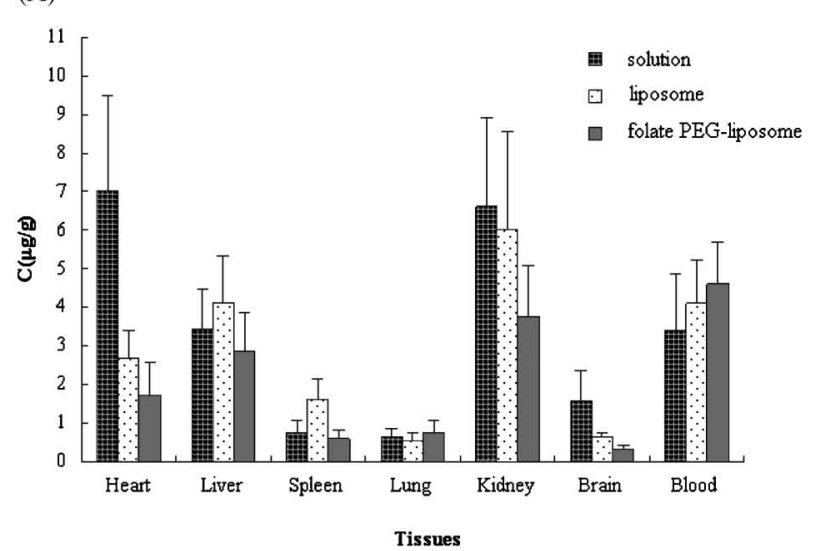

(C)

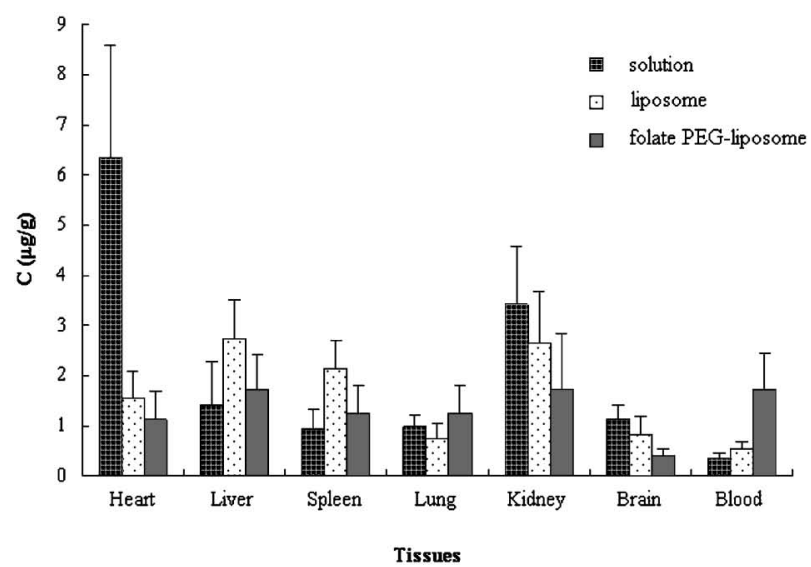

ter administration of docetaxel in solution or incorporated in liposomes are presented in Fig 3. Docetaxel was extensively distributed in all tissues assayed. The

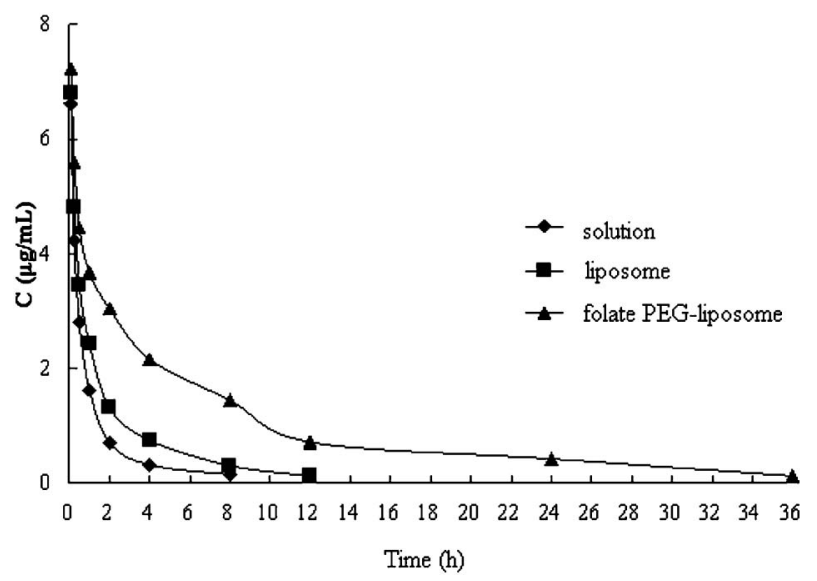

Fig. 2. Mean Plasma Concentrations of Docetaxel after I.V. Administration of the Drug Solution and Two Liposome Formulations
(B)

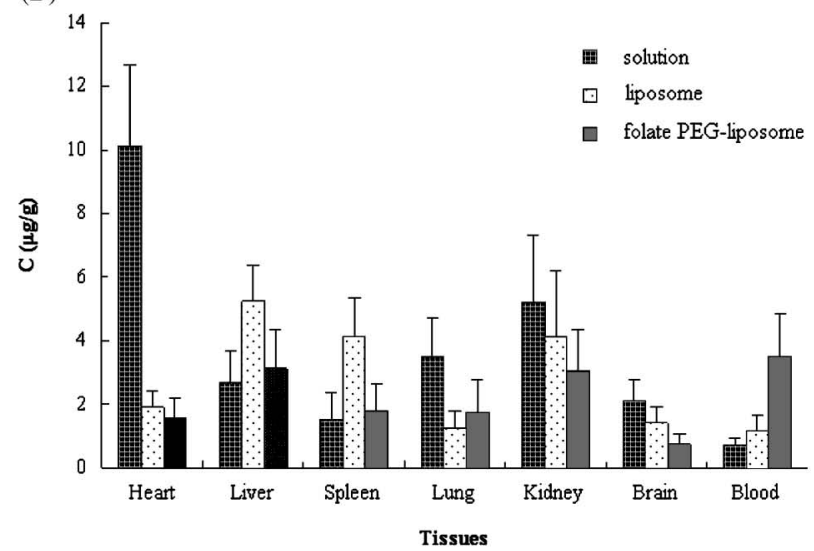

(D)

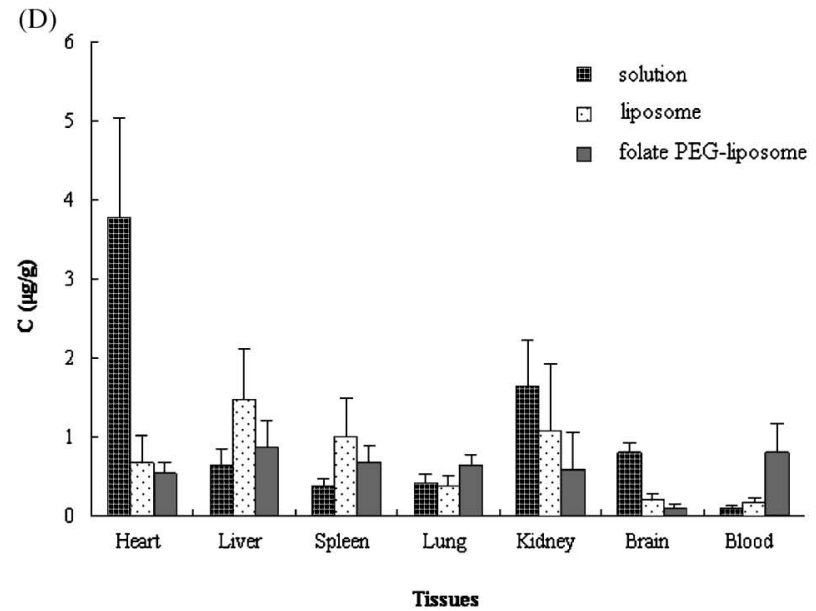

Fig. 3. Tissue Distribution of Docetaxel after I.V. Administration of Drug Solution and Two Drug Loaded Liposome Formulations to Mice

(A) $0.5 \mathrm{~h}$, (B) $2 \mathrm{~h},(\mathrm{C}) 6 \mathrm{~h}$ and (D) $12 \mathrm{~h}$. 
concentration of docetaxel was high in the heart and remained for at least $24 \mathrm{~h}$ after i.v. administration of the free drug, which might cause acute toxicity. ${ }^{16)}$ Both of the liposome formulations decreased the docetaxel concentration in the heart; this would then be expected to reduce the side effects of the drug. Compared to ordinary liposomes, folate-conjugated PEG-liposomes reduced the liver uptake of the drug and thus resulted in a prolonged blood circulation time. The folate-conjugated PEG-liposomes reduced the accumulation of docetaxel in the kidneys and the brain. These results indicate that folate-conjugated PEG-liposomes might reduce the side effects of docetaxel.

Furthermore, the folate-conjugated PEG-liposomes resulted in substantial accumulation of docetaxel in the tumor, and tumor accumulation in the folate-targeted group was significantly greater than in the other groups $(p<0.05)$ and far superior to the docetaxel solution, as shown in Fig. 4.

In Vivo Anti-tumor Activity Tumor-bearing mice were injected with docetaxel in solution or en-

Table 2. Main Pharmcokinetic Parameters of Docetaxel in Plasma after I.V. Administration of Solution and Liposomes to Rats

\begin{tabular}{lccc}
\hline \hline \multirow{2}{*}{ Parameter } & \multicolumn{3}{c}{ Values } \\
\cline { 2 - 4 } & DTX solution & DTXL & Fol-PEG-DTXL \\
\hline $\operatorname{AUC}_{(0-\mathrm{t})}(\mathrm{mg} / \mathrm{l} \cdot \mathrm{h})$ & 6.586 & 10.933 & 35.095 \\
$\operatorname{AUC}_{(0-\infty)}(\mathrm{mg} / \mathrm{l} \cdot \mathrm{h})$ & 6.633 & 11.479 & 36.474 \\
$\operatorname{AUMC}_{(0-\mathrm{t})}$ & 10.276 & 28.235 & 301.229 \\
$\mathrm{AUMC}_{(0-\infty)}$ & 12.666 & 37.225 & 366.598 \\
$\mathrm{MRT}_{(0-\mathrm{t})}(\mathrm{h})$ & 1.56 & 2.582 & 8.583 \\
$\mathrm{MRT}_{(0-\infty)}(\mathrm{h})$ & 1.91 & 3.243 & 10.051 \\
$\mathrm{t}_{1 / 2}(\mathrm{~h})$ & 1.157 & 3.08 & 7.795 \\
$\mathrm{CL}(\mathrm{l} / \mathrm{h} / \mathrm{kg})$ & 2.261 & 1.307 & 0.411 \\
\hline
\end{tabular}

Fol-PEG-DTXL, docetaxel loaded folate-conjugated PEG-liposomes; DTXL, docetaxel loaded liposome. capsulated within various different types of liposomes, and their therapeutic effects were examined by measuring the suppression of tumor growth (Table 3 and Fig. 5). The results of the statistical analysis are shown in Table 4. Tumor growth was suppressed by

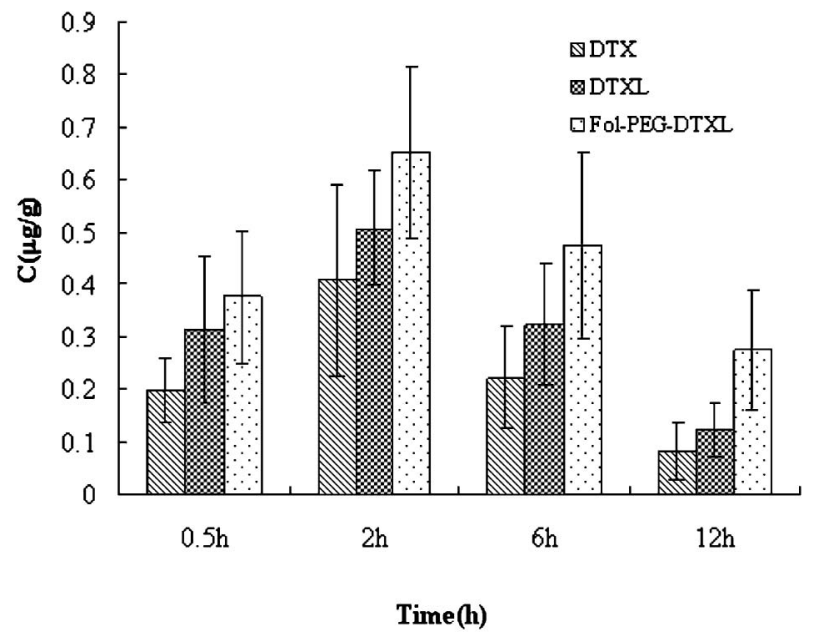

Fig. 4. Distribution of Docetaxel in Tumor Tissues after I.V. Administration of Drug Solution and Two Drug Loaded Liposome Formulations to Mice at 0.5, 2, 6 and $12 \mathrm{~h}$

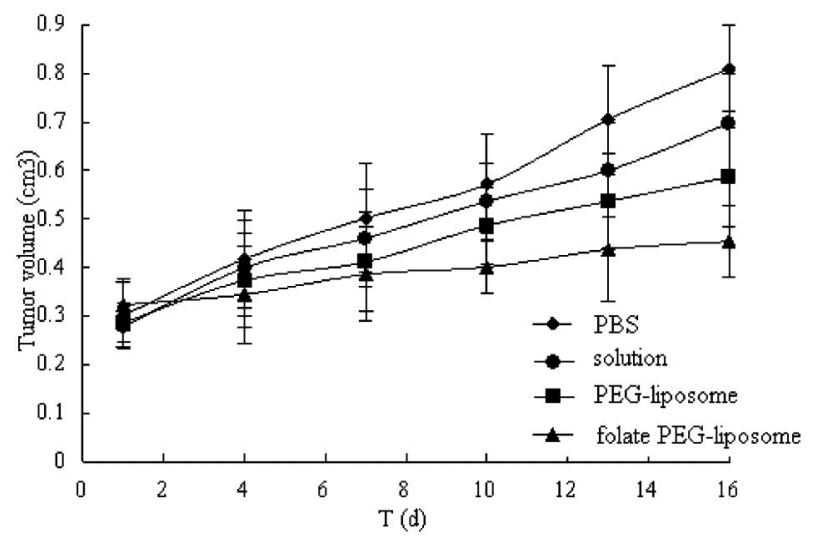

Fig. 5. Therapy Efficacies of DTX and Liposomal DTX in a $\mathrm{MCF}-7$ model $(n=5)$.

Table 3. The Effect of Various DTX Formulations on the Weight of Tumor on BALB/c Nude Mice

\begin{tabular}{|c|c|c|c|c|c|c|}
\hline \multirow{2}{*}{ Formulation } & \multicolumn{2}{|c|}{ Number of mice } & \multicolumn{2}{|c|}{ Body weight (g) } & \multirow{2}{*}{$\frac{\text { Tumor weight }}{(\mathrm{g})}$} & \multirow{2}{*}{$\frac{\text { Inhibition }}{(\%)}$} \\
\hline & Beginning & End & Beginning & End & & \\
\hline PBS & 5 & 5 & $20.24 \pm 1.48$ & $17.81 \pm 1.31$ & $0.74 \pm 0.25$ & - \\
\hline DTX & 5 & 5 & $21.11 \pm 1.57$ & $19.41 \pm 1.24$ & $0.66 \pm 0.18$ & 10.8 \\
\hline PEG-DTXL & 5 & 5 & $20.38 \pm 1.64$ & $20.34 \pm 1.63$ & $0.42 \pm 0.17$ & 43.2 \\
\hline Fol-PEG-DTXL & 5 & 5 & $19.12 \pm 1.41$ & $21.12 \pm 1.94$ & $0.24 \pm 0.10$ & 67.6 \\
\hline
\end{tabular}

DTX, docetaxel solution; Fol-PEG-DTXL, docetaxel loaded folate-conjugated PEG-liposomes; PEG-DTXL, docetaxel loaded PEG-liposomes. 
Table 4. Statistical Analysis of the Effect of Various DTX Formulations on the Weight of Tumor on BALB/c Nude Mice

\begin{tabular}{lcccc}
\hline \multicolumn{1}{c}{ Groups } & vs. A & vs. B & vs. C & vs. D \\
\hline PBS (A) & & & & \\
DTX (B) & $>0.05$ & & $<0.01$ & $<0.01$ \\
PEG-DTXL (C) & $<0.01$ & $<0.01$ & & $<0.01$ \\
Fol-PEG-DTXL (D) & $<0.01$ & $<0.01$ & $<0.01$ & \\
\hline
\end{tabular}

DTX, docetaxel solution; Fol-PEG-DTXL, docetaxel loaded folate-conjugated PEG-liposomes; PEG-DTXL, docetaxel loaded PEG-liposomes.

docetaxel in solution and encapsulated within PEGliposomes or folate-conjugated PEG-liposomes. However, the greatest suppression was observed in the case of docetaxel encapsulated within folate-conjugated PEG-liposomes.

\section{CONCLUSIONS}

To enhance the anticancer potency of docetaxel, docetaxel-loaded, folate-conjugated PEG-liposomes were prepared and evaluated. The results indicate that this kind of liposome might enhance the potency while at the same time block the side effects of docetaxel.

\section{REFERENCES}

1) Bissery M. C., Guenard D., Gueritte-Voegelein F., Lavelle F., Cancer Res., 51, 48454852 (1991).

2) Horwitz S. B., Trends Pharmacol. Sci., 13, 134-136 (1992).

3) Immordino M. L., Brusa P., Arpicco S., Stella B., Dosio F., Cattel L., J. Control. Release, 91, 417-429 (2003).

4) Farokhzad O. C., Cheng J., Teply B. A.,
Sherifi I., Jon S., Kantoff P. W., Richie J. P., Langer R., Proc. Natl. Acad. Sci. USA, 103, 6315-6320 (2006).

5) Yousefi A., Esmaeili F., Rahimian S., Atyabi A., Dinarvand R., Scientia Pharmaceutica, 77, 453-464 (2009).

6) Lee R. J., Low P. S., Biochim. Biophys. Acta, 1233, 134-144 (1995).

7) Lee R. J., Low P. S., J. Biol. Chem., 269, 3198-3204 (1994).

8) Gabizon A., Horowitz A. T., Goren D., Tzemach D., Mandelbaum-Shavit F., Qazen M. M., Zalipsky S., Bioconjug. Chem., 10, 289-298 (1999).

9) Anderson K. E., Eliot L. A., Stevenson B. R., Rogers J. A., Pharm. Res., 18, 316-322 (2001).

10) Saul J. M., Annapragada A., Natarajan J. V., Bellamkonda R. V., J. Control. Release, 92, 49-67 (2003)

11) Taylor K. M. G., Taylor G., Kellaway I. J., Stevens J., Int. J. Pharm., 58, 49-55 (1990).

12) Kirby C., Clarke J., Gregoriadis G., Biochem. J. 186, 591-598 (1980).

13) Ladbrooke B. D., Williams R. M., Chapman D., Biochim. Biophys. Acta, 150, 333-340 (1968).

14) Taylor K. M. G., Morris R. M., Thermochimica Acta, 248, 289-301 (1995).

15) Bangham A. D., Standish M. M., Watkins J. C., J. Mol. Biol., 13, 238-252 (1965).

16) $\mathrm{Xu} \mathrm{Z.,} \mathrm{Chen} \mathrm{L.,} \mathrm{Gu} \mathrm{W.,} \mathrm{Gao} \mathrm{Y.,} \mathrm{Lin} \mathrm{L.,}$ Zhang Z., Xi Y., Li Y., Biomaterials, 30, 226232 (2009). 